\section{A NOTE ON TREATMENT OF ABSCESS OF THE LIVER.}

By EUGÈNE LAURENT, B.S., M.B.Lond., M.R.C.S.EnG., Curepipe, Mauritius.

DURING the last filteen years, in the cuurse of hospital work and of private practice in the Mauritius, I have had the opportunity of observing, treating, and operating upon 110 cases of tropical abscess of the liver. I am, consequently, fully alive to the difficulty of finding some central abscesses of the right lobe, or even some abscesses of the convexity of the liver, although clinical symptoms point clearly to their presence.

Exploratory laparotomy is a severe measure,

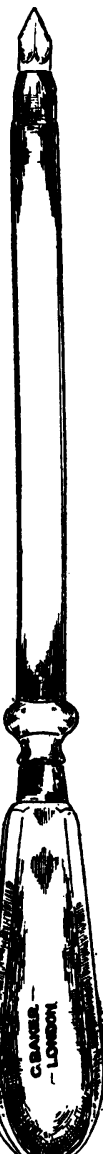
and in a genuine central abscess is of little avail. I grant, however, that it has been of great service to me in abscesses of the convexity of the liver.

Exploration by means of the trocar is the means we resort to most readily, and the trocar coupled with the aspirator is our sheet anchor in those cases. When we are fortunate enough to hit upon the purulent focus, the next step is free incision of the intercostal space, and of the healthy liver substance intervening between the abdominal wall and the abscess. This second part of the operation is frequently difficult, because when the cannula is withdrawn after the exploration, and when pus has been found, there is always a slight displacement of the liver, which might prevent the operator from getting directly into the abscess after the incision of the parietes. Another source of difficulty arises from the free bleeding of the liver substance if the operation be slow and gradual.

To obviate this, some practitioners leave the cannula in situ, and make the incisions upon it as a guide. But from personal experience I am bound to condemn such a procedure, having been an eye-witness to a sad accident : a very good surgeon having explored with the trocar and cannula the liver of one of his patients and found pus, used the round cannula as a guide to open up the liver, and thrust his knife into the intercostal artery. I have heard of two sinilar accidents happening under identical circumstances.

Struck by those mishaps, I devised the trocar and double-grooved cannula shown in the accompanying drawing. It ensures rapidity of operation, diminishes the chances of septic absorption by the bleeding liver tissue, and practically prevents all hæmorrhage, because a large drainage tube may at once be inserted, and stops any further bleeding.

The advantages which $i$ claim for my trocar are :

1. It is flat (oval on section) and therefore penetrates more readily between the ribs than the ordinary circular form.

2. It is I inch longer than the ordinary trocar and cannula of Dieulafoy. This is of great service, because on several occasions I had the moral certainty that abscess of the liver existed; I punctured in two or three different spots and found no pus.

From ten days to a fortnight after,'I explored again and found a large abscess which had come within the reach of the 4-inch trocar. The shortness of the trocar accounted for the failure of the first explorations. Mr. Cantlie, by experiments on frozen bodies, has proved that the inferior vena cava is from $4^{\frac{1}{4}}$ to 5 inches from the surface in a normal liver, and that the danger of wounding the trunk of the portal vein before it breaks up in the liver is still more remote. I accordingly feel certain that in a diseased liver, which is always enlarged, although this may not be apparent externally, the risk of injuring the above-mentioned veins is practically nil.
3. The grooves on either side of the cannula are two invaluable directors which ensure safety, precision, and rapidity of operation.

I have demonstrated practically on the dead body at the London Hospital and at the French Hospital, through the kindness of my friend Dr. Dardenne, the utility of such an instrument. It has been made for me by Mr. Charles Baker, 244, High Holborn. When the pus is very thick and cannot flow through the cannula, irrigation or aspiration can be resorted to by adapting an india-rubber tube to my cannula.

\section{UNUSUAL CASE OF MALIGNANT DISEASE IN EARLY INFANT LIFE.}

By H. J. CLARK, M.R.C.S., L.R.C.P. LoND., Swanage.

THE exceptional rarity of malignant disease in early infancy justifies the publication of the following case :

Mrs. O. was delivered of her second child in January, 1899. At birth neither testicle presented any abnormality inisize or position. When ten weeks old some enlargement of the child's left testicle became apparent wholly unassociated with any accidental cause. This enlargement was of steady growth, until at the end of eight months it had attained the size of a small hen's egg, smooth and firm to the touch and without any implication of neighbouring glands. On December $x \mathrm{gth}$, 1899, the testicle was removed in the usual way, and weighed r oz. $\mathrm{r}_{3} \mathrm{gr}$.

The accompanying drawing from a slide prepared for me by the Clinical Association shows fairly well a group of tubules with columnar-celled lining, while other spaces are empty or filled with mucoid substance.

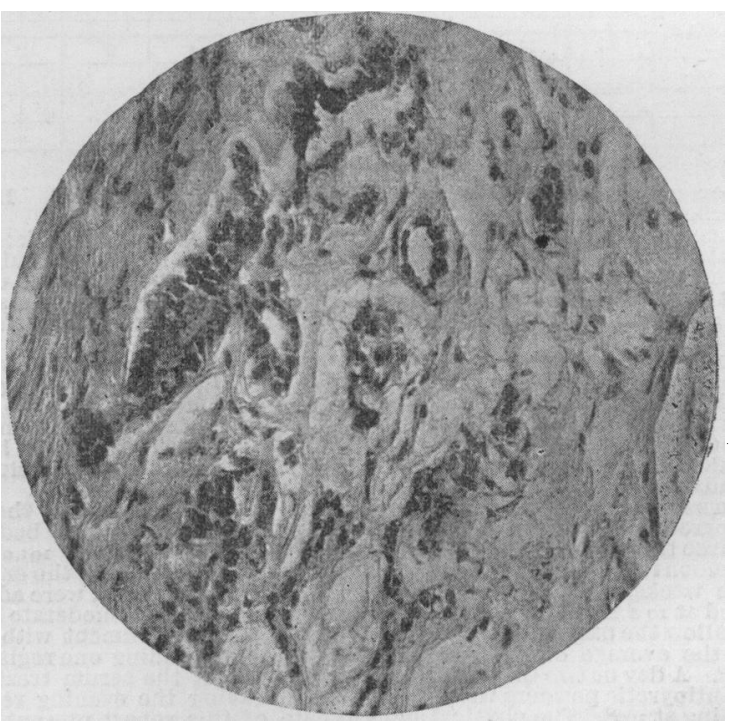

With the exception of congenital renal tumours, columnarcelled carcinoma is rare in infants. In this case neither parent presented any suspicion of malignant history.

Post-Operative Hagmatemhsis. - Dr. Kenelm Winslow has recently recorded in the Boston Medical and Surgical Journal, a case in which three days after an operation for umbilical hernia, the patient, a woman of 65 years, began to vomit blood in very large quantities, and died a few hours later. There was no lesion of the gastric mucous membrane discoverable on the most careful search, or indeed any pathological condition of importance.

The Agglotination Mrthod For TUberculosis.-M. Arloing made a communication at the recent Congress in Paris on the possibility of diagnosing early tuberculosis, before the onset of any physical signs, by means of the serumagglutination method. He consilers the method even more delicate for tuberculosis than for typhoid fever, and far preferable to the tuberculin method, because only a small drop of blood is required, and the reaction takes place in vitro and not within the body. 